CLINICAL ETHICS

\title{
Should patient consent be required to write a do not resuscitate order?
}

\section{P Biegler}

J Med Ethics 2003;29:359-363

Consent ought to be required to withhold treatment that is in a patient's best interests to receive. Do not resuscitate (DNR) orders are examples of best interests assessments at the end of life. Such assessments represent value judgments that cannot be validly ascertained without patient input. If patient input results in that patient dissenting to the DNR order then individual physicians are not justified in overriding such dissent. To do so would give unjustifiable primacy to the values of the individual physician. Therefore patient consent is effectively required to write a DNR order. Patient dissent to a DNR order should trigger a fair process mechanism to resolve the dispute.

Dr Biegler is a Staff Specialist in the Emergency Department, Sandringham Hospital, and Honorary Lecturer, Monash University, Alfred Hospital, Melbourne, Victoria, Australia

Correspondence to: Dr P Biegler, Emergency Department, Sandringham Hospital, 193 Bluff Rd, Sandringham Victoria 3191, Australia; pbiegler@bigpond.net.au

Accepted

14 November 2002
$\mathrm{T}$ he extent to which patients should be involved in decisions about them to withhold potentially life prolonging treatment has received considerable attention in journals and the lay press in recent times. In particular the notion of the "unilateral" do not resuscitate (DNR) order (it is acknowledged that some prefer the term "do not attempt resuscitation" rather than "do not resuscitate" as the former more accurately conveys the fact that survival rates after CPR are low. Estimates of the number of hospitalised cardiac arrest patients who survive to discharge, range from $6.5 \%$ to $15 \%$, see the paper by Leonard et $a^{1}$ ) where decisions are taken to withhold cardiopulmonary resuscitation (CPR) in the event of a cardiac arrest without discussion with the patient or his or her relatives, has been subject to criticism. ${ }^{2}$

Formal attempts at defining physicians' obligations in such cases have resulted in a range of conclusions. In the state of New York, for example, legislation was enacted in 1988 mandating patient consent to DNR orders. ${ }^{3}$ In the United Kingdom, however, the recent joint statement by the British Medical Association, the Resuscitation Council (UK) and the Royal College of Nursing ${ }^{4}$ falls short of requiring patient consent to DNR orders, but does advocate "sensitive exploration" of the patient's wishes regarding resuscitation. The British Medical Association recently released its updated guidelines, Withholding and Withdrawing Life Prolonging Medical Treatment, ${ }^{5}$ which take into account the effects of the Human Rights Act 1998. These guidelines also stop short of a formal consent process being applied to DNR orders, stating that "health care professionals are not obliged to provide any treatment that cannot produce the desired benefit" (BMA, ${ }^{5}$ p 21). The guidelines make clear that ultimately individual clinicians may withhold treatment if it is "contrary to their clinical judgment" or stems from a patient request that is not "reasonable" (BMA, pp 2l-2). The guidelines do, however, counsel physicians to discuss their decisions with patients.

Despite these developments, many health care professionals still argue that unilateral DNR orders are justifiable. They hold that doctors, because of their scientific expertise, are best placed to assess the "futility" of specific interventions and that once treatments are deemed futile they need neither be offered to nor discussed with patients. ${ }^{6-9}$ There is also evidence of the persistence of unilateral DNR orders in both hospitals and nursing homes. ${ }^{10} 11$ Opponents of unilateral DNR orders claim that such orders frustrate patient autonomy and represent unjustifiable paternalism on the part of the medical profession. ${ }^{212}$

I will argue that, in the case of a competent patient, a do not resuscitate order should not be written without, at least, that patient's implied consent. ${ }^{13}$

\section{CONSENT TO NON-TREATMENT}

Traditionally, the informed consent process exists to protect patients from unwanted interventions. In law, doctors who undertake invasive medical procedures without a competent patient's consent commit the tort of battery. ${ }^{14}$ To the author's knowledge, however, no definitive legal determination has been made regarding a patient's putative right to consent to or refuse an intervention being withheld. An ethical analysis of the consent process becomes necessary.

If we accept that, at its most fundamental level, the ideal of the informed consent process is to enhance the autonomous choice of patients and to prevent harm to them, ${ }^{15}$ then we might also accept that the consent process could have relevance to the notion of withholding, rather than administering an intervention, if it enhanced patient autonomy and prevented harm in such a circumstance.

An influential formulation of autonomy propounds the ideals of positive and negative liberty. ${ }^{16}$ Negative liberty implies freedom from impedance to one's actions of self determination whereas positive liberty requires that individuals be assisted in attaining their goals through the provision of appropriate resources. The consent process is more closely aligned to the concept of positive liberty. That is, rather than individuals merely being protected from procedures that 
they do not wish to undergo, they are provided with information about their medical options in an effort to enhance their ability to choose well.

If the consent process, construed as protecting autonomy under a positive liberty formulation, were to be credibly applied to the withholding of interventions, it would appear that doctors might be required not just to assist patients through the provision of information but could at times be compelled to accede to individual claims for treatment. This claim stems from the idea that if a consent process were binding, and consent to the withholding of an intervention were not forthcoming, then the required action would appear to be administration of the treatment in question.

What treatments then, might individuals be justified in requesting, and having administered, under a positive liberty formulation of autonomy? I submit that they would be justified in requesting treatments that are in their best interests. My claim arises from the precept, firmly grounded in ethics and the law, that doctors have a duty to act in their patients' best interests at all times. The strength of patients' claims for such treatments would be augmented by the doctor's duty to administer them. A patient with a clear diagnosis of bacterial pharyngitis-for example, has a strong case for requesting antibiotics and a doctor, certainly one practising under the Western medical paradigm, would hardly be justified in withholding antibiotics unless a clear contraindication existed.

Also, the withholding of a treatment that would be in the patient's best interests to receive, harms that patient.

So determination of the validity of a process of consent to the withholding of medical treatment could be grounded in the idea that patients can make justifiable claims to receive treatment that is in their best interests. The basis for a requirement of patient consent to withhold such treatment rests on the assertion that not to receive such treatment would unjustifiably frustrate patient autonomy (under a positive liberty formulation) and cause harm to that patient.

So it becomes pivotal to establish a definition of what might constitute treatment that is in a patient's best interests and, specifically in relation to DNR orders, what life prolonging treatment might be in a patient's best interests.

\section{BEST INTERESTS AND FUTILITY}

Common denominators in proposals for a best interests test include the probability that treatment will reverse the illness, the likely resultant quality of life, and how burdensome the treatment might be to the individual patient. ${ }^{17}$ These elements bear strong resemblance to those commonly cited in descriptions of the idea of medical futility. Schneiderman et al suggest that the futility of an intervention can be measured in terms of effect and benefit and from both quantitative and qualitative aspects. ${ }^{18}$ Perhaps a concise summary of Schneiderman et al's futility equation might be that it describes an intervention in terms of its probability of achieving a physiological effect and the quality of the resulting benefit to the patient.

The point that comes through emphatically in both definitions of best interests and of futility is that they are entirely susceptible to subjective interpretation, and such interpretation may differ depending on whether the perspective represented is that of the doctor or the patient. A physician-for example, might judge that a patient who is bed bound in a nursing home has such a poor quality of life and low chance of survival in the event of a cardiac arrest that cardiopulmonary resuscitation in such a circumstance would not be warranted. That patient, however, after being fully informed of information material to the decision, might quite competently accept a low survival risk and a likely resulting low quality of life and wish for resuscitation to take place. What is at odds here is the value placed on elements of the futility, or best interests equation by doctor and patient.

These observations seem to lead to the following, somewhat disquieting conclusion. If a consent process were to be applicable to the withholding of treatments that might be in a patient's best interests to receive, and the patient's subjective input were required to determine what was in his or her best interests, then consent might be required to withhold any therapy that the patient defined as being indicated. I say disquieting because such a conclusion appears to legitimise the requests of patients for treatment that may appear harmful or bizarre to the treating doctor.

Tomlinson and Brody address this concern by arguing that the presence of value judgments in futility assessments does not negate a doctor's right to make such assessments nor to use them as a basis for withholding treatment that he or she believes is against a patient's interests. ${ }^{19}$ They argue-for example, that a cardiac surgeon cannot be obliged to perform bypass surgery on a patient with angina, whom the surgeon believes has a high chance of dying on the operating table, even if that patient competently insists that he or she wishes to take the risk. To honour the request, they continue, would entail the doctor breaching his or her duty to act in the patient's best interests as the latter requires offering treatment likely to deliver a net benefit to the patient.

I would suggest, however, that this conclusion simply amounts to assigning primacy to the physician's value judgment (that a particular course of action would result in harms outweighing benefits) over the patient's value judgment (that in fact the benefits of the treatment outweigh the harms). I would dispute the validity of always according the physician's values such primacy.

\section{VALUE JUDGMENTS AND PHYSICIAN PRIMACY}

It is not difficult to find examples where the motivating values of physicians have ultimately been in conflict with the patients' interests; the tragedy of the preventable deaths that occurred in the cardiothoracic unit of the Bristol Infirmary being a prominent one. ${ }^{20}$ In such cases, what physicians regarded as an acceptable harm/benefit analysis was entirely discordant with the views of the families of patients and the community at large. Clearly neither patients' nor doctors' value systems can be looked to individually as providing a fail safe source of guidance for determining when an intervention might or might not be in a patient's best interests to receive. In response to this dilemma, Tomlinson and Brody suggest that we look towards a "societal concept of reasonableness" to guide us in seeking a value system that might usefully apply to best interests decisions at the end of life. ${ }^{19}$

A precedent for a societal standard being employed to ratify the withholding of treatment at the end of life finds form in brain death criteria. In 1968, the group commonly known as the Harvard brain death committee argued forcefully that doctors ought to be legally empowered to make decisions to terminate life support in patients with brain death, and its views were adopted as legislation in many countries around the world. ${ }^{21}$ Despite this, there remain people who do not accept that those with brain death are really dead. This belief is prominent amongst some orthodox Jews, people of Japanese descent, and Native American Indians (Beauchamp et $a l,{ }^{15} \mathrm{p} \mathrm{482}$ ). Brain death legislation effectively gives doctors a societally sanctioned right to override the goals and values of, at least some, patients and their relatives. Although this is not the case in New Jersey, where respect for the beliefs of those who dissent to the diagnosis of brain death on religious grounds has been codified in legislation which directs physicians to diagnose death based solely on cardiopulmonary rather than neurological criteria in such instances. ${ }^{22}$ 
It seems unlikely that a similar societal standard could be developed to cover the gamut of conditions that fall short of conforming to brain death criteria but nevertheless have a similarly dismal prognosis. The heterogeneous nature of the end stage physiology that ensues from conditions such as sepsis, pneumonia, cerebral haemorrhage or myocardial infarction makes them unlikely candidates for legislation, common law judgments or clear community consensus from some other forum. A societal standard would be difficult to implement uniformly to cover many conditions at the end of life.

It is difficult to justify assigning primacy to the values of patients, doctors or society in relation to end of life decision making. Before suggesting a compromise to this dilemma, I would like to address some objections to the assertion that the physician should be denied primacy over best interest assessments at the end of life.

Some authors appeal to the ideals of professional autonomy, professional integrity, and therapeutic privilege as grounding physician primacy in futility judgments. ${ }^{15}$ It has been argued that these concepts can be invoked to allow the values of the physician to be determinative in the process of end of life decision making. I will briefly examine these concepts and challenge these assertions.

\section{PROFESSIONAL AUTONOMY AND PHYSICIAN PRIMACY}

A characteristic of a profession is that practitioners typically have a degree of autonomy in their work. The idea of professional autonomy translates to a freedom to exercise individual judgment based on the knowledge and expertise the practitioner has gained in his or her discipline. As Bayles argues "if professionals did not exercise their judgment in these aspects, people would have little reason to hire them". ${ }^{23}$

It is generally accepted, however, that understanding and reasoning form only a part of the autonomy equation, and that those parts need to be applied in the context of individual values (Beauchamp et $a l^{15} \mathrm{p} 125$ ). In order to argue that the respect for professional autonomy grounds physician primacy in relation to value judgments at the end of life it would need to be shown that the physician's superior medical knowledge and expertise equated with a concomitant superiority in the assessment of values. Such an equation lacks coherence. Being good at the science of medicine doesn't necessarily translate into expertise at moral judgment for others. Physicians cannot claim a greater expertise in moral judgment than the rest of the community and if appeals to autonomy are ultimately not just knowledge fuelled but also value laden, such appeals lack coherence. Assertion of professional autonomy collapses into the problem it hopes to overcome: assertion of a value judgment.

\section{PROFESSIONAL INTEGRITY AND PHYSICIAN PRIMACY}

If appeals to physician autonomy are unsuccessful in grounding physician primacy, in cases of dispute can appeals to physician integrity be any more defensible? One definition of integrity holds that "to have integrity is to have unconditional and steady commitment to moral values and obligations" and "this moral commitment becomes a crucial component in ... [one's] identity as a person". ${ }^{24}$ Thus integrity can be thought of as a wholeness or unity resulting from concordance between one's actions and one's moral values. To act against one's values not only constitutes a moral wrong but results in feelings of self betrayal, distress, shame, and guilt. ${ }^{25}$

The problem for the assertion that professional integrity might ground unilateral futility assessments quickly becomes clear. If decisions to withhold treatment are based on the threat administration that such treatment might entail for the treating doctor's integrity, and the latter rests firmly on the foundation of the doctor's values, then this objection echoes the kind of value clash that was evident in the discussion of professional autonomy. How can the physician claim value primacy, particularly if the consequences for him or her amount to little more than psychological distress when the patient will face death as a result?

\section{THERAPEUTIC PRIVILEGE AND PHYSICIAN PRIMACY}

The concept of therapeutic privilege grants a limited discretion on the part of a medical practitioner to withhold information from a patient if the practitioner believes that its disclosure might harm that patient. There have been various legal formulations of this doctrine in which the harms to a patient are categorised either as danger to physical or mental health or impairment of decision making capacity, particularly in relation to the proposed intervention. ${ }^{26}$ Can therapeutic privilege be validly invoked to defend non-disclosure of information relating to a withheld intervention?

In relation to the risk of disclosure harming the patient's mental health, there does seem a risk that, in a patient close to death, discussion of potential resuscitation might impose an undue emotional burden. Such a burden must be considered, however, in light of the potential harms of nondisclosure. Those harms might include impaired patient autonomy and the potential for material information not being brought to light that could alter the doctor's assessment of the patient's best interests. The seriousness of these potential harms, combined with the difficulty of a doctor accurately predicting the extent of emotional harm that disclosure might cause, weigh against the use of therapeutic privilege.

Also, the risk of inducing a state that impairs decision making capacity is common to all areas where patient consent is an issue. Many other treatment discussions-for example, those involving cancer therapies, involve life and death decisions. Patients are not generally excluded from such discussions for fear that any resulting anxiety might harm them. Rather, it is through information provision and supportive care that such anxieties are diminished. Excluding competent patients from dialogue that involves a decision about whether their life should be prolonged would appear inconsistent with usual medical practice.

\section{DISPUTE RESOLUTION}

We seem to have arrived at a position that finds few reasons to justify individual physician primacy in judgments over whether treatments deemed futile by the physician can be legitimately withheld. This position is grounded in the idea that disputes over whether a treatment is warranted are in part disputes about the relative values of the individuals involved. Absolute physician primacy appears to entail placing a higher priority on the physician's values than on those of the patient. In many cases, to do so appears morally indefensible because it makes an erroneous epistemological claim that medical expertise leads to a similar expertise in assessing the merit of individual values.

How should a best interests or futility assessment be made in relation to a decision to implement a DNR order? I have suggested that neither the values of the patient, doctor, nor the community can be given individual primacy in grounding such decisions. The decision has to be made, however, and it is the treating doctor who is ultimately charged with making it.

I propose that doctors ought to derive a balanced best interests assessment in relation to DNR orders by incorporating their own views with those of the patient (if competent) in the context of prevailing community values. If doctor and 
patient are in dispute about whether a DNR order should be implemented then patients should have access to due process to resolve the dispute.

I acknowledge that the notion of doctors incorporating community values into a best interests assessment presents difficulties. How are such values to be identified? Moreover, if the community values that influence the nature of medical goals represent erroneous perceptions of what is achievable then such values as a force driving the direction of medicine might be seriously questioned. Television medical drama represents one possible source of such misperceptions. One study looked at the rate of recovery from cardiac arrest on TV programmes as compared to in life and found a dramatic improvement in survival odds for the television patients. ${ }^{27}$ On television, approximately $67 \%$ of patients suffering cardiac arrest appeared to survive to hospital discharge compared to estimates of $6.5 \%$ to $15 \%{ }^{1}$ in the medical literature.

One answer might be to encourage something akin to what Robert Veatch calls "deep value pairing". ${ }^{28}$ His approach entails pairing practitioners and patients of similar sociocultural background to facilitate convergence of values and reduce disputes. A parallel approach might target the entire community to disseminate information about the medical community's collective view of what was achievable within the current medical model. Education programmes could incorporate discussion of the nature and prognosis of CPR and the reality of the intensive care unit experience, perhaps allowing patients to make more realistic appraisals of the benefit to them of resuscitation at the end of life. They might also allow doctors to appreciate that some patients may benefit from treatment that the doctors themselves believed was futile. Such programmes could also provide a forum for community groups to feed back their concerns to the medical profession.

\section{FAIR PROCESS}

How might a fair process be implemented in the hospital setting to resolve treatment disputes at the end of life? The Council on Ethical and Judicial Affairs of the American Medical Association proposes an algorithmic approach to disagreement which involves deliberation between patients, their proxies, the treating consultant and an ethics committee, with the option of transfer to another institution if agreement cannot be reached. ${ }^{29}$ If no other institution will agree to the requested treatment they recommend that treatment be withheld. It is acknowledged that legal action may ensue if the latter course is chosen. Such an approach represents a compromise that recognises the value laden nature of futility assessments and attempts to ameliorate the potential unfairness of these assessments by appealing to a broader based set of values. The AMA's approach could act as a template for individual institutions to draft their own fair process mechanism.

Consider the example of an 80 year old man with metastatic lung cancer admitted to hospital with increasing shortness of breath and a diagnosis of pneumonia. On admission the patient refuses to consent to a DNR order and expresses the wish for intubation and ventilation in the event of cardiopulmonary arrest. The treating doctor feels such interventions to be against the patient's interests and wishes to withhold them. A fair process would focus initially on enhancing communication between doctor and patient in an attempt to achieve a concordance of values. The experience of Murphy suggests that such an approach can be effective. ${ }^{6} \mathrm{He}$ describes how, in response to the question: "Would you want us to do everything possible to save your life if your heart stopped beating?" most patients in his unit of a chronic care hospital requested that CPR be administered. When, however, he altered the approach to one that disclosed the reality of the patient's prognosis, what CPR precisely entails, and the specifics of the intensive care unit experience, 23 of 24 patients declined CPR. Forestalling accusations of "framing" information in such a way as to subliminally persuade patients to adopt his preferred course, he had a senior nurse critique each discussion. The implication of Murphy's findings is that if doctors openly communicate their reasons for wishing to withhold certain therapies it is likely that the patient's views will converge with their own.

If agreement were not reached after these efforts a second clinician could be asked to assess the case and give an opinion as to whether attempted resuscitation would be in the patient's interests. If this clinician supported the patient's treatment preference a transfer of care could be arranged. If the second clinician concurred with the views of the first a next step might be to involve a clinical ethicist as mediator. If disagreement persisted then a hospital regulatory body, perhaps a patient ethics committee which included lay representation, could convene to arbitrate the dispute.

Clearly, this type of review would be untenable where a patient faces imminent death and there is no time to set the process in train. If this were the case in our example, would the attending physician be "forced" into administering treatment that he or she regarded as against the patient's best interests as a default response to the unresolved dispute? I do not believe so. The fair process approach at no stage mandates individual physicians treating against their perceived views of the patients' interests and there ought not to be, nor could there be, any means of compelling doctors to do so. If the attending physician in the example withheld treatment in accordance with his or her best interests assessment then that decision would be open to review, a process that might well ultimately support the doctor's action. Such an approach ought not to be seen as persecutory but simply an extension of a system where any decision a doctor takes is open to retrospective review to determine its probity.

\section{TRIGGERING A REVIEW PROCESS}

Physicians may be concerned that the preceding discussion indicates that all disputed care plans for patients need to go through a process of arbitration and that a physician is never justified in rejecting any requested treatments, no matter how absurd, out of hand. I would like to address these concerns by proposing three standards that physicians might adopt as guidance for when third party scrutiny should be sought for decisions to withhold therapies in the face of patient dissent. I propose that a review process should be triggered when one or more of the following conditions obtain:

- The withheld therapy might reasonably be expected to be administered by society and/or the patient in the circumstances;

- Death will be hastened as a result of therapy being withheld, and

- Therapy is withheld after specific deliberation by the health care team.

If these conditions do not obtain I submit that physicians ought to be able to withhold, without third party review, treatments requested by patients if those physicians assess the requested treatment as not being in the patient's best interests to receive. These standards are proposed because they allow for the administration of a broad ambit of therapies that might be in a patient's best interests to receive while at the same time ruling out review processes for bizarre treatment requests. 
The first standard recognises the importance of both patient and community values in the best interests assessment. The second standard recognises the gravity of decisions to withhold potentially life-prolonging therapies. The third standard alludes to the notion that therapies that require a specific decision on the part of the health care team to be withheld are likely to hold equivocal status in relation to the patient's best interests and prudence would suggest that they not be withheld unilaterally.

\section{CONCLUSION}

The preceding discussion has, I hope, substantiated several points. Firstly, consent ought to be required to withhold treatment that is in a patient's best interests to receive. This argument is grounded in the notion that the consent process exists to protect patient autonomy and prevent harm. Withholding therapies that are in a patient's best interests to receive frustrates that patient's autonomy (under a positive liberty formulation) and harms him or her.

Assessments of treatment futility at the end of life have strong parallels with assessments of best interests. The significance of the value judgments implicit in assessments of futility cannot be determined without patient input. This observation strongly challenges the idea that a unilateral futility assessment could have validity and implies an obligation on the part of health care professionals to inform patients of therapies that they plan to withhold. Neither respect for physician autonomy, physician integrity, nor the concept of therapeutic privilege constitute justifiable reasons for making unilateral futility judgments.

If the patient dissents to treatment being withheld then initial attempts at resolving the conflict should focus on efforts at enhanced communication. Failure to resolve conflict with these measures should trigger a fair process approach to dispute resolution. Recognition that physicians should be empowered to make certain value judgments to withhold therapies without the need for third party review leads to the proposal of three standards. It is suggested that doctors ought to seek third party review of decisions to withhold treatment in the face of patient dissent when: the withheld therapy might reasonably be expected to be administered by society and/or the patient in the circumstances; death will be hastened as a result of therapy being withheld, or therapy is withheld after specific deliberation by the health care team. In the absence of these criteria I submit that a doctor ought to be able to act on his or her value judgment and withhold therapy that is believed to be futile or not in the patient's best interests.

All DNR orders will relate to withholding treatment that conforms to the third standard and many will proscribe treatment that conforms to the other two standards. The corollary of this observation is that patient dissent to a DNR order ought not to be overridden by an individual physician. Effectively, this means patient consent is required to write a DNR order. It is my view, however, that implied, rather than express consent should be the requisite standard. That is, if a competent patient is informed that a treatment is to be withheld and does not dissent then implied consent ought to be allowed to be assumed. This specification stems from reports of distress occurring among elderly patients required to sign consent forms to the withholding of life prolonging therapy. ${ }^{30}$ It also serves to balance the ideal of respect for autonomy with the sensitivity that health care professionals should demonstrate when dealing with patients nearing the end of life.

\section{REFERENCES}

1 Leonard CT, Doyle RL, Raffin TA. Do not resuscitate orders in the face of patient and family opposition. Crit Care Med 1999;27:1045-7.

2 Ebrahim S. Do not resuscitate decisions: flogging dead horses or a dignified death? BMJ 2000;320:1 155-6.

3 New York State Public Health Law. Article 29-B, section 2964 http:// assembly.state.ny.us/leg/?cl=91\&a=148 (accessed 17 Sept 2003).

4 British Medical Association, Resuscitation Council (UK), Royal College of Nursing. Decisions relating to cardiopulmonary resuscitation: a joint statement. London: BMA RC (UK), RCN, 2001

5 British Medical Association. Withholding and withdrawing life prolonging medical treatment: guidance for decision making. London: BMJ Books, 2001.

6 Murphy DJ. Do not resuscitate orders: time for reappraisal in long term care institutions. JAMA 1988;260:2098-101.

7 Hackler C, Hiller CF. Family consent to orders not to resuscitate; reconsidering hospital policy. JAMA 1990;264:1281-3.

8 Layson RT, McConnell T. Must consent always be obtained for a do not resuscitate order? Arch Intern Med 1996;156:2617-20.

9 Ditillo BA. Should there be a choice for cardiopulmonary resuscitation when death is expected? Revisiting an old idea whose time is yet to come. J Palliat Med 2002:5:107-16.

10 Mello $M$, Jenkinson C. Comparison of medical and nursing attitudes to resuscitation and patient autonomy between a British and an American teaching hospital. Soc Sci Med 1998;46:415-24.

11 Levin JR, Wenger NS, Ouslander JG, et al. Life sustaining treatment decisions for nursing home residents: who discusses, who decides, and what is decided? J Am Geriatr Soc 1999;47:82-7.

12 Youngner SJ. Who defines futility? JAMA 1988;260:2094-5

13 Biegler $\mathbf{P}$, Stewart $C$. Assessing competence to refuse medical treatment. Med J Aust 2001;174:522-5.

14 Kennedy I, Grubb A, eds. Principles of medical law. New York: Oxford University Press, 1998:110.

15 Beauchamp TL, Childress JF. Principles of biomedical ethics. Oxford: Oxford University Press, 1994:142.

16 Berlin I. Two concepts of liberty. In: Four essays on liberty. Oxford: Oxford University Press, 1969.

17 Luttrell S. Making decisions about medical treatment for mentally incapable adults in the UK. Lancet 1997;350:950-3.

18 Schneiderman LJ, Jecker NS, Jonsen AR. Medical futility: its meaning and ethical implications. Ann Intern Med 1990;112:949-54.

19 Tomlinson T, Brody H. Futility and the ethics of resuscitation. JAMA 1990;264: 1276-80.

20 Dyer C. Bristol inquiry. BMJ 2001;323:181.

21 Report of the ad hoc committee of the Harvard Medical School to examine the definition of brain death. A definition of irreversible coma. JAMA 1968;205:85-8.

22 New Jersey Permanent Statutes, title 26:6A-5 http://www.njleg.state.nj.us/ (accessed 17 Sept 2003).

23 Bayles MD. Professions and professionalisation. In: Callahan JC, ed. Ethical issues in professional life. New York: Oxford University Press, 1988:28.

24 Honderich T, ed. The Oxford companion to philosophy. New York: Oxford University Press, 1995.

25 Blustein J. Doing what the patient orders: maintaining integrity in the doctor patient relationship. Bioethics 1993;7:289-314.

26 Skene L. Law and medical practice: rights, duties, claims, and defences. Sydney: Butterworths, 1998:149.

27 Diem SJ, Lantos JD, Tulsky JA. Cardiopulmonary resuscitation on television: miracles and misinformation. N Engl J Med 1996;334:1578-82.

28 Veatch R. Abandoning informed consent. Hastings Cent Rep 1995;25:5-12.

29 Council on Ethical and Judicial Affairs, American Medical Association. Medical futility in end of life care. JAMA 1999;281:937-41.

30 Baker R, Strosberg MA, Bynum J, eds. Legislating medical ethics: a study of the New York State do not resuscitate law. Dordrecht: Kluwer Academic Publishers, 1995:80, 293 